\title{
LEVANTAMENTO DAS MANIFESTAÇÕES PATOLÓGICAS DO TEATRO MUNICIPAL DE CASCAVEL - PR
}

\author{
PAGANIN, RICARDO \\ Engenheiro Civil \\ Centro Universitário Assis Gurgacz \\ Paraná; Brasil \\ engpaganin@gmail.com
}

\author{
RACHID, LIGIA ELEODORA FRANCOVIG \\ Engenheira Civil \\ Centro Universitário Assis Gurgacz \\ Paraná; Brasil \\ ligia@fag.edu.br
}

\author{
WELTER, DHEIME FATIMA \\ Engenheira Civil \\ Centro Universitário Assis Gurgacz \\ Paraná; Brasil \\ dheimewelter@gmail.com \\ BASSO, THALYTA MAYARA \\ Engenheira Civil \\ Centro Universitário Assis Gurgacz \\ Paraná; Brasil \\ thalytabasso@hotmail.com
}

\section{RESUMO}

Estudos prévios identificaram que existem problemas de qualidade e desempenho em edificações de obras públicas e, tais problemas são cada vez mais recorrentes nesse tipo de empreendimento, que podem estar relacionados ao processo de desenvolvimento do produto ou a falhas na execução. Neste contexto, o objetivo desta pesquisa foi levantar as manifestações patológicas presentes na edificação do Teatro Municipal Sefrin Filho, localizado na cidade de Cascavel PR, visto que a sua construção foi iniciada no ano de 1991, e a obra foi entregue no ano de 2015. Os objetivos específicos do trabalho referem-se à identificação dos diferentes tipos de manifestações patológicas aparentes, a determinação das possíveis causas dos problemas, a provável origem, além da verificação da frequência dos mesmos. $\mathrm{O}$ trabalho foi realizado baseando-se na vistoria do local e registros fotográficos, para posterior embasamento na literatura para identificação dos problemas e classificação do grau de risco. Através da pesquisa, verificou-se que $67 \%$ das falhas tiveram como origem erros de execução, $28 \%$ erros de projeto e $5 \%$ nos materiais utilizados. Com relação a frequência de manifestações patológicas verificou-se que as eflorescências representaram 52\% dos problemas encontrados, observou-se ainda, que $68 \%$ dos problemas são de grau de risco baixo, $17 \%$ médio e $15 \%$ de grau de risco alto. As manifestações patológicas classificadas na pesquisa como sendo de grau de risco alto demandam atenção, visto que oferecem riscos aos usuários da edificação estudada, resultado este, que evidencia a importância de realizar manutenções para assegurar a durabilidade da edificação.

Palavras-chave: obras públicas, teatro, patologia, frequência, risco.

\section{ABSTRACT}

Previous studies have identified that there are quality and performance problems in public works buildings and such problems are increasingly recurring in this type of development, which may be related to the product development process or execution failures. In this context, the objective of this research was to survey the pathological manifestations present in the building of the Municipal Theater Sefrin Filho, located in the city of Cascavel - PR, since its construction began in 1991 and the work was delivered in 2015. The specific objectives of this work are the identification of the different types of apparent pathological manifestations, the determination of the possible causes of the problems, the probable origin, and the verification of their frequency. The work was performed based on site inspection and photographic records, for later basis in the literature to identify the problems and classification of the degree of risk. Through the research it was found that $67 \%$ of the failures originated from execution errors, $28 \%$ design errors and $5 \%$ in the materials used. Regarding the frequency of pathological manifestations, it was found that efflorescence represented $52 \%$ of the problems found. It was also observed that $68 \%$ of the problems are low risk, $17 \%$ medium and $15 \%$ high risk. The pathological manifestations classified in the research as being of high degree of risk demand attention, since they offer risks to the users of the studied building, which shows the importance of performing maintenance to ensure the durability of the building.

Keywords: public works, theater, pathology, frequency, risk. 


\section{INTRODUÇÃO}

As obras públicas são uma categoria de projetos de infraestrutura e tem como objetivo mudar o cenário social e econômico de um País, para fins recreativos, empregatícios ou de saúde e segurança, as mesmas provêm, a princípio, das demandas da população, advindas da necessidade de proporcionar algum benefício à coletividade para seu uso comum (FARIAS, 2016). Ainda segundo Farias (2016), as obras públicas se sobressaem aos demais empreendimentos governamentais, revelando à população seu sucesso ou insucesso, é o tipo de ação administrativa visível aos olhos da população, podendo marcar para sempre a história de uma gestão.

A construção do Teatro Municipal de Cascavel - PR teve início no ano de 1991, uma obra da Prefeitura Municipal, feita em parceria com o Governo do Estado do Paraná. No primeiro mandato do ex-prefeito Salazar Barreiros, a secretaria da cultura realizou um concurso para a escolha do melhor anteprojeto para a construção do teatro.

Depois de Salazar o prefeito da época Fidelcino Tolentino, decidiu ampliar o projeto, que então passaria de 2.545,43 $\mathrm{m}^{2}$ para 5.923,58 $\mathrm{m}^{2}$. Em junho de 2008 o então prefeito Lísias de Araújo Tomé iniciou a obra civil (prédio). Em janeiro de 2009, quando a administração Edgar Bueno assumiu a prefeitura, deparou-se com um projeto de obra civil ultrapassado e fora das normas atuais de construção. A readequação dos projetos alterou praticamente toda a estrutura interna do prédio. Passados 24 anos a obra foi entregue pelo ex-prefeito Edgar Bueno, no ano de 2015, passando por sete gestões. Desde então, o edifício vem apresentando manifestações patológicas.

Manifestações patológicas nas edificações são alterações anatômicas e funcionais causadas no edifício. Estas anomalias podem ser adquiridas durante a concepção do projeto, a execução da obra pelo emprego inadequado de materiais e métodos construtivos, ou mesmo serem adquiridas ao longo de sua vida, onde suas principais causas afetam o desempenho da edificação ou os tornam inadequados aos fins a que se destinam, causando prejuízo material e dano ao consumidor (SILVA, 2007).

Segundo o Código de Defesa do Consumidor, Lei $\mathrm{n}^{\mathrm{o}}$ 8.078/90, o construtor responde pelos danos causados, independentemente, da existência de culpa pela reparação aos consumidores finais, por defeitos decorrentes de projetos, construção, bem como por informações insuficientes ou inadequadas sobre sua utilização e riscos. O defeito causa danos ao patrimônio jurídico, material e estético.

Consequentemente, Souza e Ripper (1998) relata que o correto é que exista certo cuidado para que não ocorram tais erros, evitando perdas. No entanto, se houver a ocorrência de manifestações patológicas, faz-se necessário a investigação dos sintomas, bem como as causas e origens do problema, que são itens fundamentais para o diagnóstico da situação e tratamento do problema.

Nesse contexto, este trabalho desenvolveu o levantamento das principais manifestações patológicas existentes no Teatro Municipal Sefrin Filho, na cidade de Cascavel-PR. Objetivando a identificação dos fatores de possíveis causas e prováveis origens dos problemas.

\section{METODOLOGIA}

A pesquisa abrangeu a coleta de dados para obter o diagnóstico das falhas e a mesma ocorreu por meio da constatação in loco das manifestações patológicas aparentes existentes no edifício, do histórico da edificação e projetos. Foi utilizado também referencial bibliográfico para embasar as conclusões em relação aos problemas identificados.

\subsection{Caracterização da amostra}

O Teatro Municipal Sefrin Filho trata-se de uma instituição pública, tendo como entidade mantenedora o governo Municipal de Cascavel - PR, sendo caracterizado como um espaço multicultural, é o segundo maior teatro do estado do Paraná com 5923,58 $\mathrm{m}^{2}$ de área construída, dividida em cinco pavimentos servidos por elevadores e demais adicionais de acessibilidade. O teatro promove várias apresentações teatrais durante toda semana, também conta com escolas que oferece aulas de teatro, dança, música, artes e cinema que recebe diariamente um fluxo grande de pessoas. A edificação está localizada na Rua Rio de Janeiro 905, Centro, Cascavel - PR, como pode ser observado na Figura 1. 


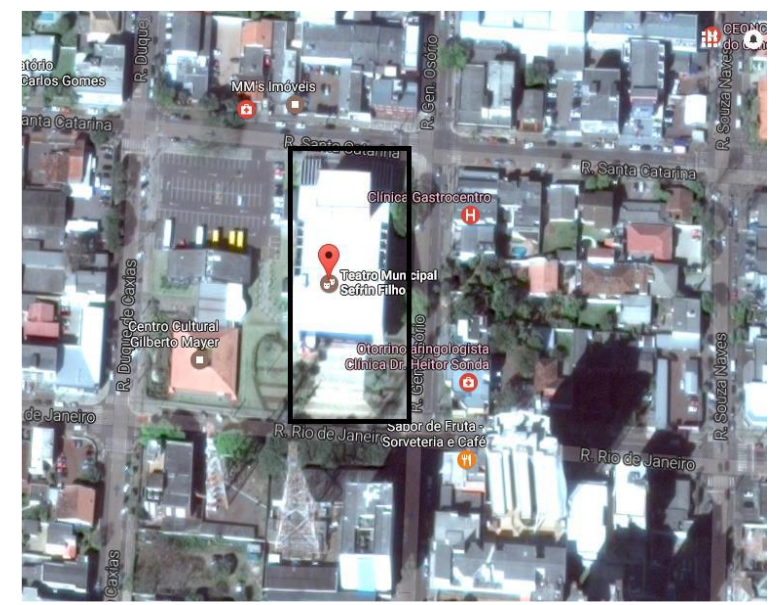

Figura 1: Localização da edificação objeto da pesquisa.

A edificação possui um sistema de construção convencional moldado in loco formado por vigas e colunas para sustentação do peso, lajes de concreto e preenchimento de tijolos e revestimentos. O processo de execução da obra levou aproximadamente 16 anos para ser finalizado. Segundo o histórico os projetos básicos do teatro foram iniciados em 1991.

Na gestão municipal de 1993 a 1996, o projeto foi ampliado para absorver um centro de eventos incorporado ao teatro, sendo sua área ampliada de 2.545,43 $\mathrm{m}^{2}$ para 5.923,58 $\mathrm{m}^{2}$, que culminou com a estrutura atual. No final da gestão municipal de 1997 a 2000, o projeto foi licitado e em 1999 iniciou-se a construção da fundação e parte da estrutura. Durante a execução da obra foram realizadas atualizações e readequações sucessivas para soluções arquitetônicas e especificações técnicas de sistemas e materiais.

No início da gestão do prefeito Edgar Bueno entre 2001 e 2004, o governo do estado não liberou verbas para a continuidade da obra, obrigando a construtora a paralisar a obra. Na gestão 2005 a 2008 o Governo do Estado liberou verbas para a execução da parte civil do Teatro de Cascavel. Com a iminência da liberação desta verba, apressadamente a Secretária de Obras Públicas - SESOP, promoveu a licitação da mesma, porém os projetos complementares estavam defasados, datavam de 1991 e não atendiam as normas vigentes da época. Isto gerou o pedido de aditivo no contrato da obra pela construtora.

A obra foi iniciada com base no projeto arquitetônico atualizado, mas os projetos complementares defasados promoveram algumas incongruências no projeto original, gerando espaços não aproveitados pela inclinação da cobertura. A obra foi então entregue para população no ano de 2015 , com áreas inacabadas e apresentando falhas no desempenho.

\subsection{Instrumentos e procedimentos para coleta de dados}

A coleta de dados teve início na solicitação dos projetos via protocolo realizado junto a Secretária de Planejamento (SEPLAN) da cidade de Cascavel - PR. Após está solicitação iniciou-se as visitas ao local, efetuando o levantamento de subsídios necessários para elaborar um diagnóstico de falhas na edificação, para tanto foram identificados os sintomas das manifestações patológicas. Também nesta etapa procurou-se detectar as causas intrínsecas e extrínsecas precedentes aos processos de deterioração da edificação de modo a proporcionar um entendimento dos problemas.

Durante a visita ao local, fez-se o registro fotográfico dos problemas patológicos e o mapeamento das manifestações patológicas. As manifestações patológicas foram classificadas conforme o grau de risco, utilizando a metodologia descrita na Norma de Inspeção Predial do Instituto Brasileiro de Avaliações e Pericias de Engenharia (IBAPE, 2012), a escala de gravidade é dividida em três níveis: crítico, regular e mínimo.

\subsection{Análise dos dados}

Após a coleta de dados, foi realizada a respectiva análise direcionada pela revisão bibliográfica existente inerente ao tema, para atingir o diagnóstico das falhas e a determinação das causas e origens. Os dados foram tabulados em 
quadros, divididos por ambientes e pavimentos, trazendo informações da classificação das manifestações patológicas, o local de ocorrência, quantidade de ocorrências, aspectos observados, possível causa, grau de risco e possível origem, para que os resultados pudessem ser melhor observados e compreendidos foram representados na forma de gráficos, confrontando-os com o referencial teórico.

Para definição da conduta do problema, foram considerados os indícios de falhas empregadas envolvendo todas as atividades realizadas durante o processo de produção e utilização que, de alguma maneira, possam ter contribuído para o surgimento dos problemas na edificação realizando assim um diagnóstico. Assim como, foi utilizando embasamento teórico para determinação da ação.

\section{ANÁLISES E DISCUSSÕES}

\subsection{Manifestações patológicas identificadas na edificação}

Dentre os problemas patológicos identificados, as eflorescências foram mais recorrentes, por abranger uma grande área e manifestar-se em diversos pontos da laje do fosso da orquestra. Tal situação pode ser observada na Figura 2.

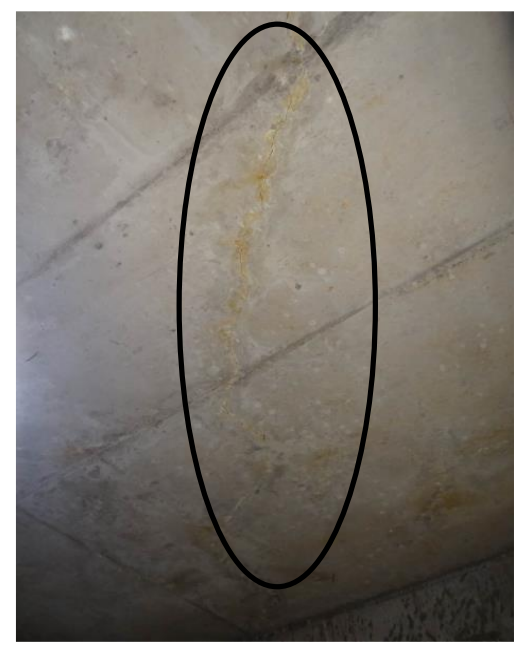

Figura 2: Eflorescências na laje do fosso da orquestra.

As eflorescências são resultado da eliminação de sais solúveis presentes no interior dos materiais, os quais na presença de água se solubilizam e migram para a superfície, formando um depósito salinos (SOUZA, 2008). Nesse caso, observase que a presença de fissuras na laje corroborou para a infiltração de umidade e eliminação destes sais para a formação de eflorescência.

O processo de eliminação de sais característicos do concreto é conhecido como lixiviação. A água atua no concreto hidrolisando a pasta de cimento, tendendo a dissolver os componentes da pasta que contém cálcio, carreando a solução hidrolisada para a superfície da peça afetada (SANTOS, 2014). No caso atual o problema foi classificado de risco mínimo, porém há uma tendência de que se ações preventivas não forem tomadas a situação possa evoluir para uma situação crítica. Em relação a origem, considerou-se que a presença em excesso de sais solúveis nos materiais utilizados para a execução foi determinante para o surgimento do problema.

As fissuras são o tipo de manifestação patológica que mais causa desconforto e preocupação aos leigos, afeta o desempenho da edificação e sua estética. Se manifestam por meio do resultado de tensões excessivas que sobrepujam a capacidade resistente dos materiais.

Durante a visita realizada, pôde-se constatar que as trincas e fissuras encontradas na edificação foram causadas, em geral, devido a quatro situações: deformação excessiva da estrutura, recalque diferencial de fundação, retração plástica do concreto e sobrecargas não previstas em projeto. Em sua maioria, os problemas não afetam a estabilidade da estrutura, porém podem causar a sensação de desconforto aos usuários.

As fissuras contínuas foram as mais típicas manifestações observadas no teatro, estão presentes em todos os pavimentos nos pisos e paredes, com o exemplo que pode ser observado na Figura 3, ela se apresenta por toda extensão da junta de 
dilatação, que são juntas intermediárias projetadas para aliviar tensões geradas por movimentações da parede e/ou do próprio revestimento, devido a variações de temperatura ou por deformação lenta do concreto da estrutura revestida.

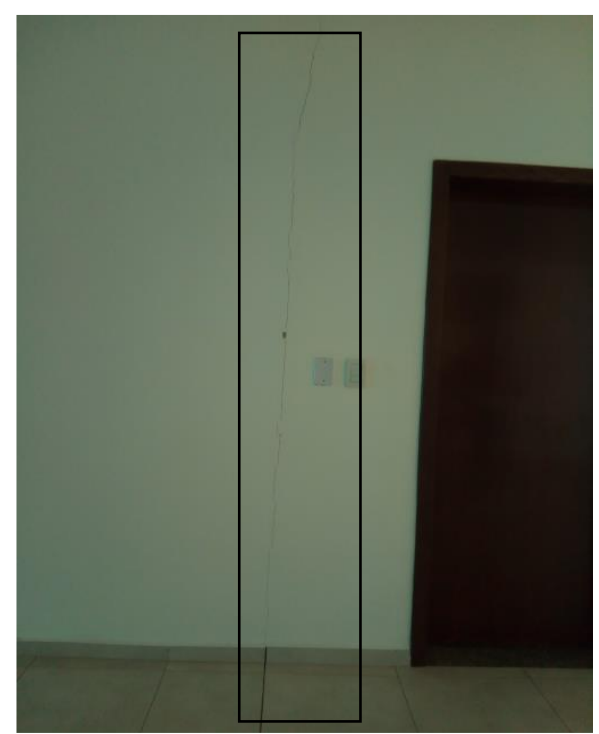

Figura 3: Fissura contínua na junta de dilatação da edificação.

Sabe-se que os materiais que compõe uma edificação, assim como o concreto podem sofrer variações de temperatura, isso pode acontecer tanto no estado fresco quanto no estado endurecido (ASSIS e RABELO, 2013). Logo, uma das prováveis causas para o surgimento dessa manifestação patológica é a ineficiência da junta de dilação em absorver os esforços de movimentações diferenciais da estrutura.

Essa manifestação patológica foi classificada como sendo de risco mínimo, visto que a mesma não induz a perda de estabilidade estrutural, ou de resistência da mesma. Nesse caso ainda pode-se atribuir que o problema pode ter origem tanto na etapa de projeto quanto na etapa de execução, visto que a junta de dilatação pode ter sido mal projetada ou mal executada.

Outro problema identificado foram as fissuras, trincas e rachaduras, presentes na área da bilheteria, essas manifestações patológicas existentes nesse ambiente foram causadas por recalque diferencial e o indicativo é de que são decorrentes da má execução de aterro, que levou a interdição dessa área para reforma a fim de recuperar o ambiente. Tal situação pode ser observada na Figura 4.

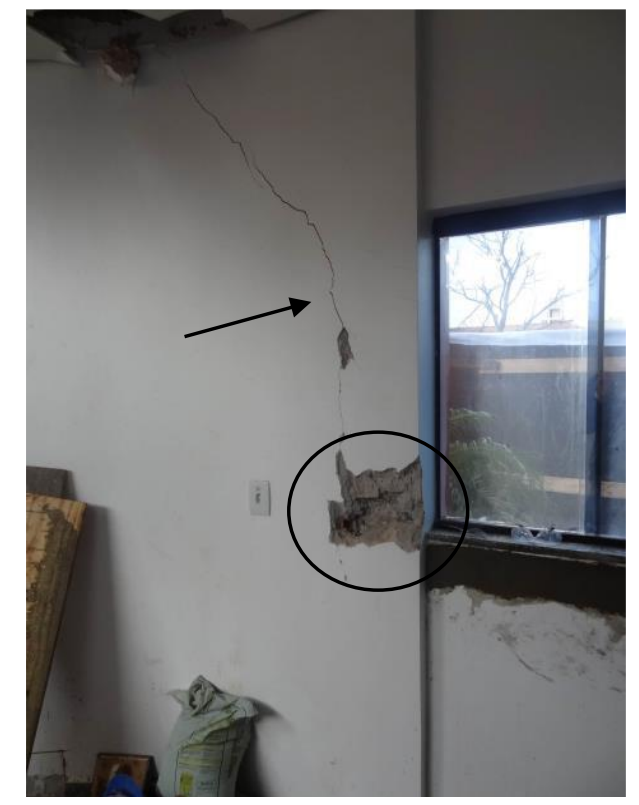

Figura 4: Fissura inclinada na parede de alvenaria da bilheteria da edificação. 
De acordo com Milititsky, Consoli e Schnaid (2015), o recalque em fundações ocorre quando há o rompimento da resistência de contato entre o solo e a fundação, isso leva a um afundamento maior do que o projetado. Essa situação pode ocorrer em toda a fundação (recalque total) ou em pontos (recalque diferencial). Nesse caso foi observado que se trata de um recalque diferencial da fundação, visto que as fissuras e problemas intensificam-se na bilheteria.

As fissuras geradas por um processo de recalque diferencial tendem a apresentar uma configuração inclinada, porém na maioria das vezes geralmente são aberturas maiores, outra característica dos processos de recalque é a presença de pontos com esmagamento localizado (THOMAZ, 1989). Além das características da fissura de recalque diferencial, observou-se também a fissuração dos vidros da porta da edificação próximos ao local, assim como uma rachadura na viga baldrame, como pode ser observado na Figura 5.

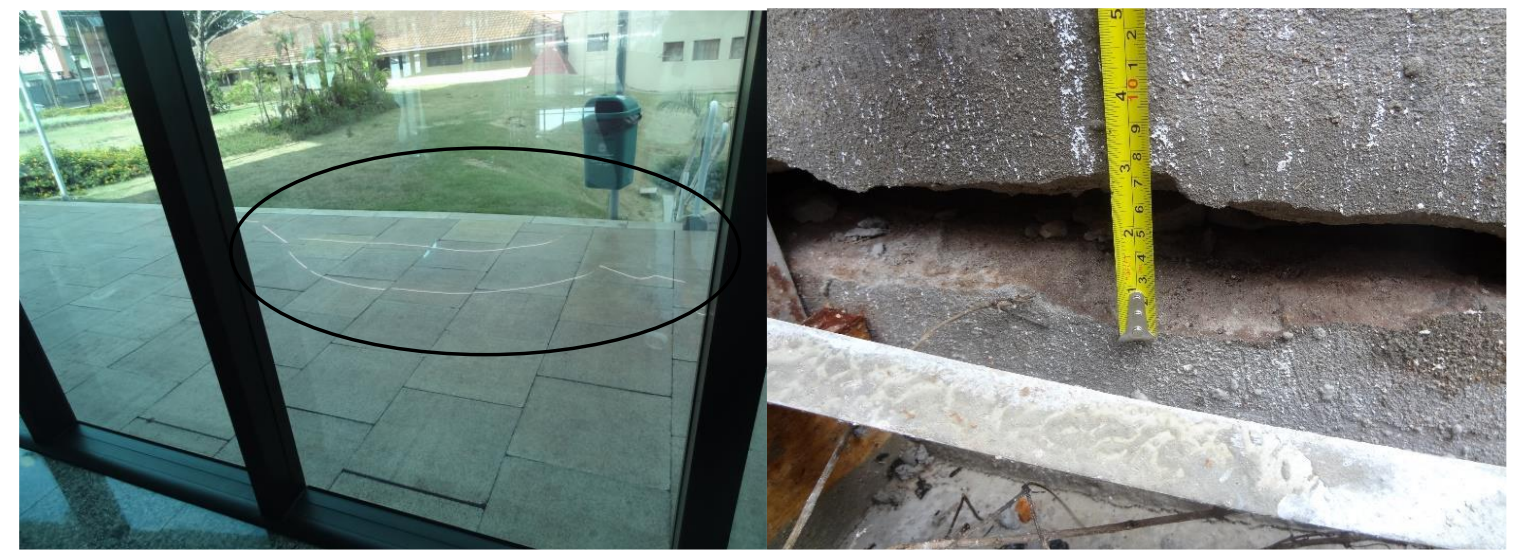

Figura 5: Fissuras nos vidros da porta da edificação próxima ao local de recalque diferencial.

A manifestação patológica de recalque pode ser considerada de grau de risco crítico, pois além de gerar insegurança para os usuários da edificação, pode comprometer a estabilidade da estrutura. Esse levou a interdição da região afetada e a ação de métodos de recuperação do problema.

A partir do levantamento de informação para determinação da causa e origem do problema patológico, constatou-se por anamnese do caso que próximo ao local onde foi construída a bilheteria do teatro havia uma árvore (pinheiro de grande porte), porém ao longo do processo de execução o mesmo foi retirado. Tal situação pode ser observada na comparação das imagens da construção na Figura 6.

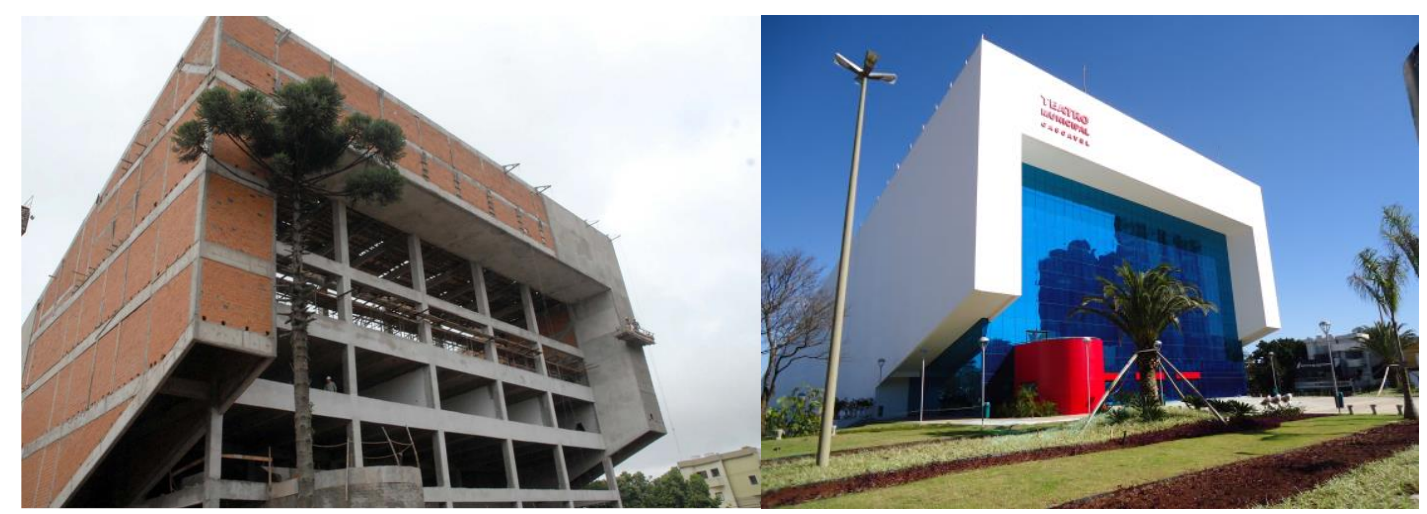

Figura 6: Comparação dos tempos de construção, demonstrando a remoção da vegetação.

Pode-se então definir que o recalque diferencial de fundação manifestou no teatro devido a erro na consolidação do aterro, onde o solo se deformou com o emprego de cargas solicitadas pela construção da bilheteria. Visto que a estrutura tende a descarregar cargas sobre o solo e devido à presença de vazios da camada mal adensada impôs distorções aos elementos estruturais, assim consequentemente a solicitação excessiva de esforços na alvenaria ocasionado pela deformação excessiva da estrutura foi a causa da abertura de fissuras, trincas e rachaduras. Dessa forma pode-se atribuir que o problema teve origem na execução, visto que o processo de compactação do solo foi prejudicado. 
Durante a vistoria da obra também pode-se identificar outros erros de execução no local onde ocorreu o recalque diferencial. Um dos exemplos observados refere-se à execução do emboço, o qual apresentou espessura média de 9 cm, como pode ser observado na Figura 7.

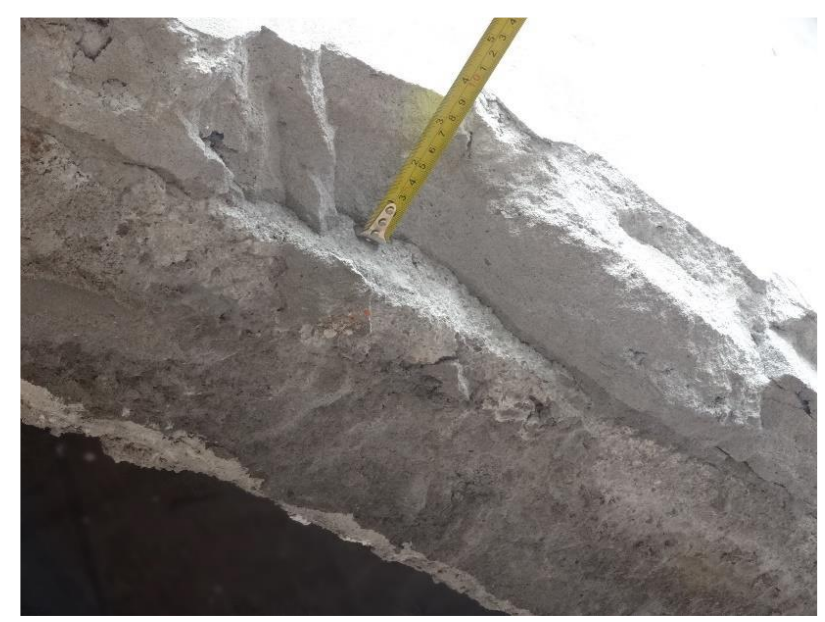

Figura 7: Espessura de $9 \mathrm{~cm}$ no emboço da bilheteria.

Aa espessura elevada do emboço pode ocasionar um peso excessivo para a estrutura o que, consequentemente, pode levar a sobrecarga da estrutura e prejudicar a aderência do revestimento, visto que a espessura recomenda pela NBR 13749 (ABNT, 2013), que trata de revestimentos de paredes e tetos com argamassas inorgânicas varia de 2 a $3 \mathrm{~cm}$. Além disso a NBR 13749 (ABNT, 2013) recomenda que para espessuras superiores devem ser tomados cuidados adicionais para garantir a aderência do revestimento, como por exemplo a utilização de reforço de tela metálica na argamassa. A espessura do revestimento argamassado não foi verificada em outros pontos da edificação devido a impossibilidade de rompimento do mesmo.

\subsection{Frequências e origens dos problemas patológicos}

As patologias são modificações estruturais e/ou funcionais, tudo que promove a degradação do material ou de suas propriedades físicas e ou estruturais. Pode-se comparar as patologias das construções a vícios como: trincas, rachaduras, fissuras, manchas, descolamentos, deformações, rupturas, corrosões, eflorescência, infiltração, entre outras. Por meio dos dados levantados pelo mapeamento das manifestações patológicas, pode-se levantar a frequência dos problemas, conforme disposto no gráfico da Figura 8.

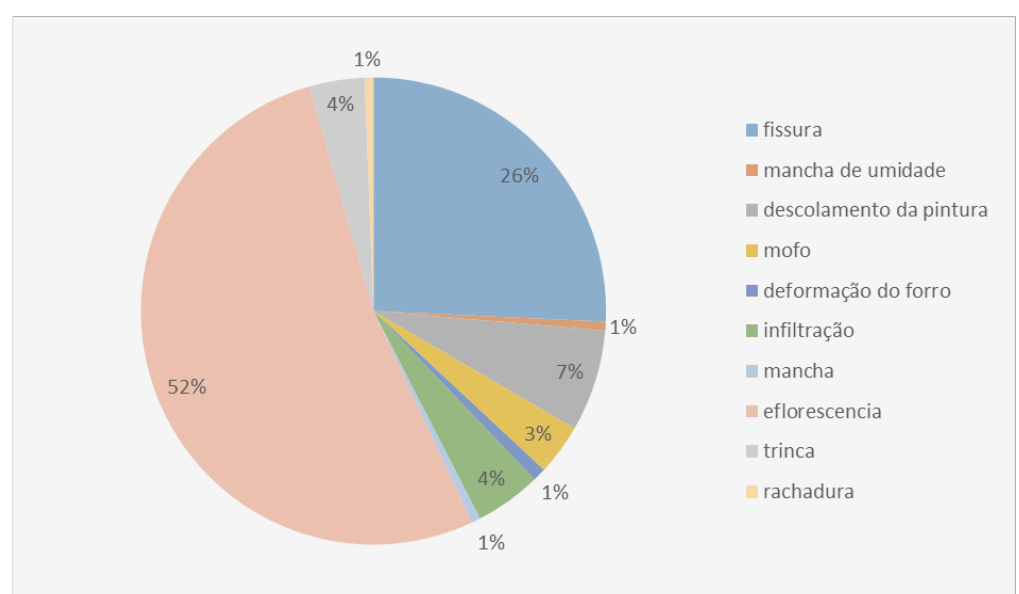

Figura 8: Frequência das tipologias de manifestações patológicas na edificação.

De acordo com os dados obtidos, a manifestação patológica com maior frequência na edificação em estudo são as eflorescências que representam $52 \%$ dos problemas, visto que sua maior ocorrência se encontra na laje do fosso da orquestra. Outra manifestação com frequência significativa é a fissura, a qual representa $26 \%$ das manifestações patológicas levantadas, seguido do descolamento da pintura com $7 \%$ de incidência e da infiltração (4\%). 
Afim de obter melhor percepção dos problemas teatro, foram levantadas as prováveis origens causadoras dos mesmos. Um resumo do levantamento pode ser observado na Figura 9.

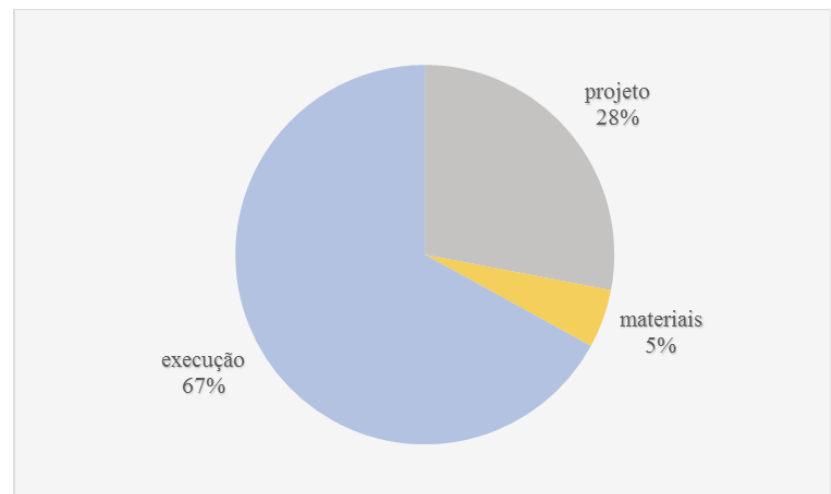

Figura 9: Frequência das origens dos problemas patológicos na edificação.

As manifestações patológicas podem ser explicadas em razão da não conformidade do produto final. Originadas em função de falhas no projeto e na execução em geral. Conforme representado no gráfico, $67 \%$ dos erros empregados na construção do teatro são de execução, seguidos de projeto com $28 \%$ e $5 \%$ emprego de materiais com má qualidade.

Percebe-se que a idade da obra não é um fator influente nas ocorrências dos problemas, pois os sintomas foram constatados pela primeira vez assim que a obra foi entregue, desconsiderando a origem dessas manifestações pelo uso da edificação. Houveram pelo menos duas modificações de projeto isso pode justificar a identificação de manifestações patológica oriundas de erros de projeto e execução.

\section{CONSIDERAÇÕES FINAIS}

Procurando contribuir com a melhoria das obras de gestão pública, deixando-as mais seguras, funcionais e duráveis, foram abordadas neste estudo, manifestações patológicas detectadas numa edificação de gestão pública. A partir dos estudos realizados, pode-se concluir que as manifestações patológicas que tiveram maior frequências foram: eflorescência com $52 \%$, fissuras $26 \%$, descolamento da pintura $7 \%$, infiltração e trinca $4 \%$, mofo $3 \%$, deformação do forro, mancha e rachadura representam $1 \%$.

Observou-se que a grande maioria das manifestações patológicas só se tornam ativas com a presença de umidade. Dessa maneira, quando chove ocorre infiltrações ou absorção de água no material agravando o problema, também é a principal percursora de outras manifestações patológicas.

Observou-se que embora a grande maioria dos problemas sejam relativos a eflorescência e infiltrações, a questão do recalque diferencial destaca-se por ser classificada como de risco crítico, visto que pode levar a deficiência na estabilidade da estrutura. Tal situação levou a administração municipal a realizar a interdição do local e a recuperação da estrutura, a qual já foi realizada. Além disso, pode-se concluir que quanto as origens dos problemas patológicos, a execução teve uma maior frequência com $67 \%$ das manifestações patológicas, seguido de $28 \%$ erros de projeto e $5 \%$ materiais.

Sendo assim, para manter a qualidade, a segurança, a vida útil e o desempenho esperado das edificações, é de suma importância a realização de trabalhos que estudem as manifestações patológicas, suas causas e meios de prevenção para que forneçam subsídios aos profissionais da construção civil. Podendo auxiliar os mesmos nas ações tomadas, para que estes ajam de maneira preventiva e planejem todas as etapas constituintes do processo construtivo.

\section{AGRADECIMENTOS}

Os autores gostariam de agradecer a todos que colaboraram para o desenvolvimento desse trabalho. Além disso, podese destacar o trabalho do Centro Universitário Assis Gurgacz, da cidade de Cascavel-PR no desenvolvimento da pesquisa. 


\section{REFERÊNCIAS}

ASSIS, F. F. de; RABELO, G. Q. Fissuras por movimentação térmica em estruturas de concreto armado. 2013. 74 f. Trabalho de Conclusão de Curso (Graduação em Engenharia Civil) - Universidade Federal de Goiás, Departamento de Engenharia Civil. Goiânia, GO, Brasil, 2013.

FARIAS, P. P. P. Licitações e Obras Públicas. Disponível em: < https://www.crea-pr.org.br/ws/wpcontent/uploads/2016/12/licitacoes-e-obras-publicas.pdf $>$. Acesso em: 12 de out. 2017.

INSTITUTO BRASILEIRO DE AVALIAÇÕES E PERÍCIAS. Norma de Inspeção Predial Nacional 2012. Disponível em: http://ibape-nacional.com.br/biblioteca/wp-content/uploads/2012/12/Norma-deInspe\%C3\%A7\%C3\%A3o-Predial-IBAPE-Nacional.pdf. Acesso em: 17 de out. de 2019.

MILITITSKY, J; CONSOLI, N. C; SCHNAID, F. Patologia das fundações. 2. ed. São Paulo: OFICINA DE TEXTOS, 2015.

SANTOS. C. F. dos. Patologia de estruturas de concreto armado. 2014. 91 f. Trabalho de Conclusão de Curso. (Graduação em Engenharia Civil) - Centro de Tecnologia, Universidade Federal de Santa Maria, Departamento de Engenharia Civil. Santa Maria, RS, Brasil, 2014.

SILVA, A. F. Manifestações patológicas em fachadas com revestimentos de argamassa. Estudo de caso em edifício em Florianópolis. 2007. 190 f. Dissertação (Mestrado em Arquitetura e Urbanismo) - Universidade Federal de Santa Catarina, Centro Tecnológico em Arquitetura e Urbanismo. Florianópolis, SC, Brasil, 2007.

SOUZA, V. C. M.; RIPPER, T. Patologia, recuperação e reforço de estruturas de concreto. 1. ed. São Paulo: PINI, 1998.

SOUZA, Marcos Ferreira de. Patologias causadas pela umidade nas edificações. 2008. $64 \mathrm{f}$. Monografia (Especialização em Construção Civil) - Escola de Engenharia da Universidade Federal de Minas Gerais, Departamento de Engenharia de Materiais de Construção. Belo Horizonte, MG, Brasil, 2008.

THOMAZ, E. Trincas em edifícios: causas, prevenção e recuperação. 1. ed. São Paulo: PINI, 1989. 